\title{
EMPLOYEE ENGAGEMENT AND EMPOWERMENT AS GATEWAY TOWARDS RETENTION: THE CASE OF VOLKSWAGEN GROUP
}

\author{
Rommel Pilapil Sergio \\ Canadian University Dubai, UAE \\ Maria Rylova \\ Canadian University Dubai, UAE
}

\begin{abstract}
Two themes of best human resource management practices -- employee empowerment and engagement have been considered a fundamental tool to increase the retention within any organization. This research paper utilized a qualitative-descriptive design through secondary sources of data collection, which centered on the case of Volkswagen Group, its retention rates and various programs offered to employees. The analysis establishes the link between employee retention and the two variables of employee empowerment and engagement. It has been revealed that employee empowerment and engagement are significant links to retention. Moreover, both empowerment and engagement contribute to a more open, innovative environment, faster decision-making, and more importantly, create loyalty and organizational commitment. The company under study serves as an excellent example of high retention rates as well as a company that focuses a lot on its employees and their happiness within the organization despite its concerns in the past.
\end{abstract}

Keywords: Employee engagement, Empowerment, Retention, Volkswagen Group

DOI: http://dx.doi.org/10.15549/jeecar.v5i2.242

Employee retention is one of the hardest challenges for many organizations in today's world. The turnover comes with a lot of costs and a new employee does not guarantee the success of the position. Therefore, companies try to come up with new and more innovative ways and programs to maintain and retain the right employees (Haladay, Sergio, Makki, Zarim, \& Ismail, 2017; Haladay, Sergio, Opulencia, \& Antiado, 2015; Sergio, Moyalan, Al-Ali, \& Al Bannai, 2017; Sergio, Ormita, Dungca, \& Gonzales, 2015; Gernal, Sergio, \& Al Shuali, 2013; Gernal, Sergio, \& Al-Rawahi, 2011). The process starts with recruitment; however it is not enough to hire the best person for the job. That is why employee engagement and empowerment can be the key to ensuring that individuals are motivated and satisfied with their jobs. Employee engagement involves motivating and inspiring employees to contribute to the organization whereas empowerment is more concerned with giving employees the authority to make the decisions. Hence, the two concepts together can significantly affect the job satisfaction because of employees' drive to do their work and more 
power to make decisions, and as a result decrease turnover rates (Haladay, et al.; Haladay \& Sergio, 2016; Sergio, et al., 2015).

In this paper, the discussion centralizes on Volkswagen Group, which is one of the leading manufacturers in the world of different car brands. The parent company is known as Volkswagen AG and it includes brands such as, but not limited to, Audi, Porsche, Bentley, Skoda, Seat, etc. The company started its production in 1937, introducing the first car "Beetle" that was developed with the help of Porsche Engineering Group by the request of Adolf Hitler himself. Volkswagen was portrayed as "the people's car" for German citizens (Henderson \& Reavis, 2009), however now the company operates on most of the continents and has 120 locations all over the world. The company has sold more than 10 million cars and commercial vehicles with the help of more than 600 thousand employees.

The purpose of this research is to find the link between Volkswagen's retention of employees and different programs that the company employs. Hiring new employees should have a strategy to make sure that the best employees are retained within the organization. Moreover, it is important to understand whether those programs and benefits are related or focused on employee engagement and empowerment. It has been expounded in this paper that Volkswagen paves its way to changing their strategy through its human capital efforts and through possible recommendations when implementing the key variables in business operations.

\section{REVIEW OF LITERATURE}

This section is divided into three parts and covers the concepts that include employee engagement, empowerment, and retention. Each part states the importance and implications when implementing the concepts within the organization as well as ways that the company can improve itself.

\section{Employee Engagement}

Nowadays competition in the market is high; therefore being successful and staying competitive is an advantage that employee engagement can provide, assuming that the organization has the right implementation and design of the program (Prerana, 2017; Saks \& Gruman, 2014). Employee engagement contributes to the organization and the employees themselves on so many levels. Individuals feel invested in the company and their work as well as have increased levels of performance and output, and as a result, have much higher job satisfaction (Increasing employee engagement, 2015). The sense of belonging contributes to fewer chances of engaged employees leaving the organization (Increasing employee engagement, 2015). One of the studies has suggested that employee engagement has a significant relation to organizational commitment (Prerana, 2017). The bond created between employees and organization will impact overall companies' image and performance. Besides, employee engagement has also been linked to higher profitability, shareholders return, and customer satisfaction (Saks \& Gruman, 2014).

The workplace is associated with a lot of responsibilities, tension, and stress. Highly engaged employees are more ready for stressful work both emotionally and physically (Increasing employee engagement, 2015). On the other hand, employee engagement can be hard to measure since there are no existing tools, and even the definitions and the meaning of the term are very broad (Saks \& Gruman, 2014). Moreover, some might argue that employee engagement is an outcome rather than an input (Guaspari, 2015).

Since the term is vague and broad, one of the studies suggested breaking employee engagement into three categories, which include task, group/team, and organizational engagement (Saks \& Gruman, 2014). Task or job engagement is concerned with the drive that employee has towards completing his/her dayto-day activities at work; team/group is an engagement level that an employee has towards the group; organization engagement is the level to which employees engage as a member of the organization. Hence, breaking down engagement allows seeing in which level individuals are engaged, because one might be driven to complete the task but ignore the team duties (Saks \& Gruman, 2014).

\section{Improving Employee Engagement}

There are various improvements that the company can implement in order to increase the engagement levels within the organization. Research suggests that some employees have stated when leaving the organization that the 
reasons were due to having routine work and being able to do much more than what they were given (Increasing employee engagement, 2015). Hence, it is important to keep employees busy with work but allow them to do some of the work on their own, and providing different tasks rather than the same work repeatedly (Increasing employee engagement, 2015; Prerana, 2017). Moreover, a friendly environment where everyone can express their thoughts and ideas should be a priority to promote empowerment of employees, and if supervisors/managers feel that the employees are not competent enough, provide training (Increasing employee engagement, 2015). The training could allow employees to establish communications with other subordinates and promote values of the organization while establishing a feeling of security (Increasing employee engagement, 2015; Saks \& Gruman, 2014; Sergio, et al., 2017; Sergio, et al., 2015).

\section{Employee Empowerment}

Employee empowerment in simple terms is known as a shift in power to the employee in lower levels in the hierarchy of the organization (Ukil, 2016). One of the challenges that organizations face with the increase in globalization and competitive markets is to increase productivity and respond to customer faster while maintaining satisfaction (Ghosh, 2013). Therefore, lack of authority and complicated organizational systems can decrease organizational ability to perform. Empowering employees allows the organization to achieve the desired productivity but also improves the quality of the service and customer communication (Ghosh, 2013).

Employees that stay in the organization for a long period of time already have knowledge of the processes and the skills required to accomplish the tasks (Ukil, 2016, Sergio, et al., 2017). Hence, depending on the level of the employee, shifting a certain power and allowing the employees to participate in the decisionmaking process will not only allow them to have more creative and innovative ideas, but also increase job satisfaction levels (Ukil, 2016; Ghosh, 2013). The stress of work tasks will be divided, creating a friendlier environment and increasing efficiency and effectiveness levels of the organization.

However, there might be some challenges and resistance to change when promoting employee empowerment. First and most importantly is the management approach, because some companies might have a higher power distance or managers might simply not want to share the power at hand (Ukil, 2016; Appelbaum et al., 2014). Another problem could be employees themselves accepting power just to pass the time at work, or having the lack of desire, willingness, or skills to use the authority given to them (Ukil, 2016).

\section{Improving Employee Empowerment}

It is obvious that employee empowerment can significantly contribute to organizational performance and employee satisfaction (Sergio et al., 2015), however, due to the reasons mentioned above it can be a struggle for the company. Therefore, the company should consider the following:

- Awareness programs which include extensive information on the importance of empowerment and its implications within the organization (Ukil, 2016)

- Provide training for both lower level employees and managers to build competencies and change the attitudes and styles of leading, including the introduction of transformational leadership (Ukil, 2016; Younge, \& Marx, 2016). Transformational leadership will allow the employees to reach their potential and encourage them to participate in the decision-making process while continuously improving their knowledge and skills (Younge \& Marx, 2016).

- Change the organizational culture if required. Some companies might have a very high distance of power; however, to have employee empowerment it is important to have a culture that is relying on trust and openness with flow of innovative ideas (Ukil, 2016).

Therefore, changing the organization to empower employees is what companies need to take into consideration to utilize and achieve a higher potential of their employees and improve overall performance (Ukil, 2016; Appelbaum et al., 2014).

\section{Employee Retention}

Employee retention is the responsibility of the company to retain their best performers or risk losing them (Frank, 2015). The turnover costs 
associated with each employee are high and are considered the largest unknown costs that an organization can face (Paillé, 2013). Most companies focus only on costs associated with the daily tasks such as supplies, for example, however many ignore or don't take into consideration how much turnover can cost to the organization (Frank, 2015; Paillé, 2013). Moreover, the use of technology is rising and the need for advanced professionals with adequate skills does too, but what organizations do not understand is that the efforts are the same for attracting and retaining employees (Sandhya \& Kumar, 2014). Retaining employees is one of the hardest challenges that organizations face in today's world (Sergio, et al., 2015, Sergio, et al., 2017).

In the data of information on employee engagement and empowerment, it is noted that through increased job satisfaction, companies can retain their employees easier. However, there are six factors that can contribute to higher retention rate for previous generations as well as Y generations. These include mentoring, career development, job satisfaction, style of management, work environment, and nature of working (Frank, 2015). Job satisfaction is the main link between retention and engagement and empowerment, however, the importance of style of management, work environment and nature, and career development (Haladay \& Sergio, 2016) are also contributed to by both concepts.

In order to improve employee retention, the company needs to keep certain implications in mind, which include but are not limited to (Paillé, 2013):

- Hiring the right people at the right time

- Empowering employees and treating them as valuable assets to the organization

- Providing training, necessary knowledge, and information

- Trusting, respecting and having faith in the individuals that have been chosen

- Providing feedback on performance as well as recognizing achievements

- Keeping the standards and morale of the employees high

\section{RESEARCH OBJECTIVES}

There is no formula for employee retention, and every organization uses different techniques to ensure that individuals do not want to leave the company intentionally. Although some might believe that retention has to be dealt with on a case-to-case basis because of the variety of reasons that employees might have, it might get harder when the company starts to develop or expand. However, establishing the foundation to keep individuals satisfied where everyone knows the significance of the day-to-day tasks and the direction in which the organization is going is undeniably important. With this in mind, the following objectives were raised for this study:

1. To ascertain the link between Volkswagen employee turnover and the current programs employed.

2. To determine how employee engagement and empowerment can help in increasing retention rates of the company.

\section{Methodology}

This research is designed to address data that was found in extensive sustainability reports of Volkswagen. The secondary sources of data have been analyzed and interpreted in the results and discussion section in a relevant and meaningful format. The paper utilized qualitativedescriptive design and the numbers found in Volkswagen reports have been used only to support the facts and potential arguments that may arise. In order to answer the research questions, researchers focused on the current practices of human resources and their relationship to employee engagement and empowerment. Hence, the data on retention rates support the research in understanding whether the company can be successful in decreasing turnover rates without the help of the two concepts or if employee engagement and empowerment are given a high priority by the company and have contributed to its high retention rates.

One of the assumptions in this research paper is that the data published by Volkswagen Group is reliable and accurate, and has not been changed or presented to misguide and show the company in a better light. Therefore, we can identify the potential links between the concepts but the results can be more subjective in terms of the analysis of the data and its meaning towards the organizational performance. 


\section{Results and Discussion}

In this section of the report, the researchers looked into the strategy that has been introduced by Volkswagen; its targets and objectives. Since this research is focused on employee engagement and empowerment, the focus has been given to the part of the strategy called "Excellent Employer" under Volkswagen Strategy Towards 2025 (Volkswagen Goals and Strategies, 2016), and the HR practices involved in the process. The last part of the section has dissected the retention rates of Volkswagen Company and the relation to employee engagement and empowerment.

Employee engagement and empowerment: Volkswagen Strategy Towards 2025

In 2015, the Volkswagen scandal took place where software engineers have faked test results to meet targets, and later it was found out that it was more than few individuals (Crête, 2016). However, it affected the organization on all levels and led to layoffs, no hiring, and a company whose image was ruined by simple misconduct.

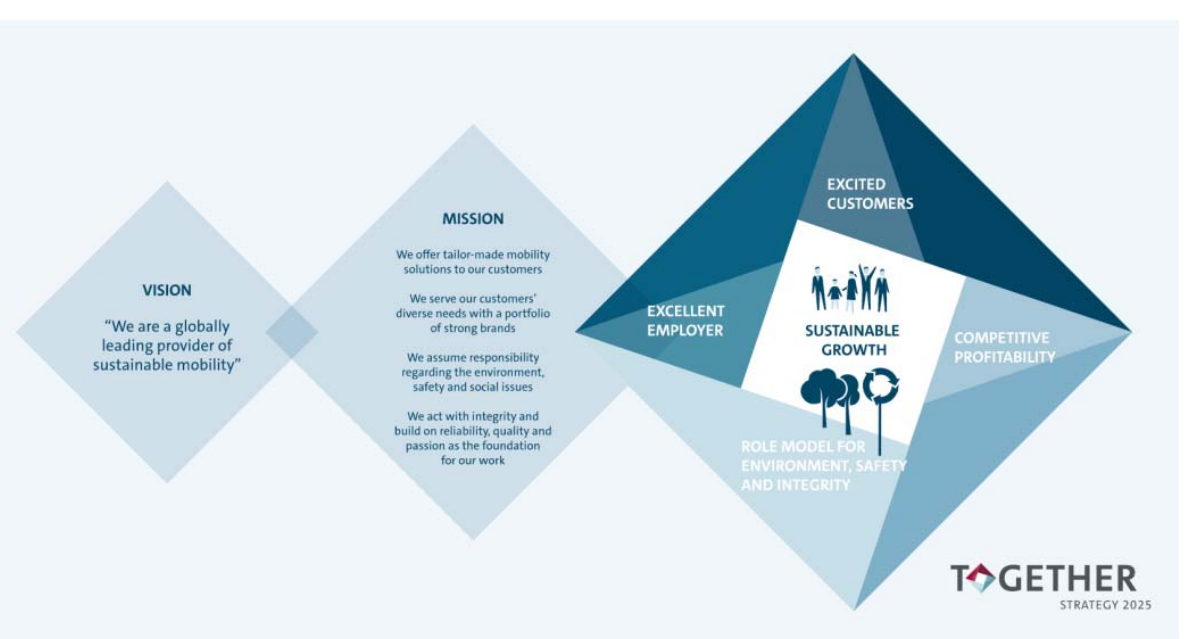

Figure 1. Together Strategy 2025 (Volkswagen Goals and Strategies, 2016)

In June 2016 (Volkswagen Goals and Strategies, 2016), Volkswagen announced a new strategy for the next decade that includes 4 dimensions (strategic objectives) as shown in Figure 1: Excellent employer, Excited customers, Competitive Profitability, and Role model for the environment, safety, and integrity. When the objectives are followed, the results set by the organization should be achieved which represent the center of the strategy. Each of the dimensions is a complex combination of different steps, programs and improvements put together in order to contribute to the goal of sustainable growth.

\section{On "Excellent Employer"}

The program "Excellent Employer" (Volkswagen Goals and Strategies, 2016) is the heart and one of the strategic objectives, and it includes four main subsections as shown below in Figure 2 to make the strategy work: Skilled and dedicated employees, First class HR organization, Outstanding corporate and leadership culture, and Sustainable labor organization. As it was mentioned by Volkswagen the Human Resources dimension uses a strategy of - "We empower to perform."

The second part includes "Skilled and dedicated employees" which is seen by VW as a commitment where employees participate, take initiatives and seek improvement. The strategic objectives include systematic skills development, career development for graduates, and training opportunities, among many other programs. In Appendix 3, the graphic shows one of the programs known as Idea Management. This program was implemented and the results achieved where VW has saved 435 million euros in 2016 because of ideas generated by employees. In order to achieve Sustainable labor organization, VW has given a great importance to the design of the workplace and hours. The objective includes giving jobs to disabled people as well as making sure that all of the resources of the 
organization are barrier-free to access. Moreover, the company has also introduced flexible working hours, so that employee can have a better work-life balance.

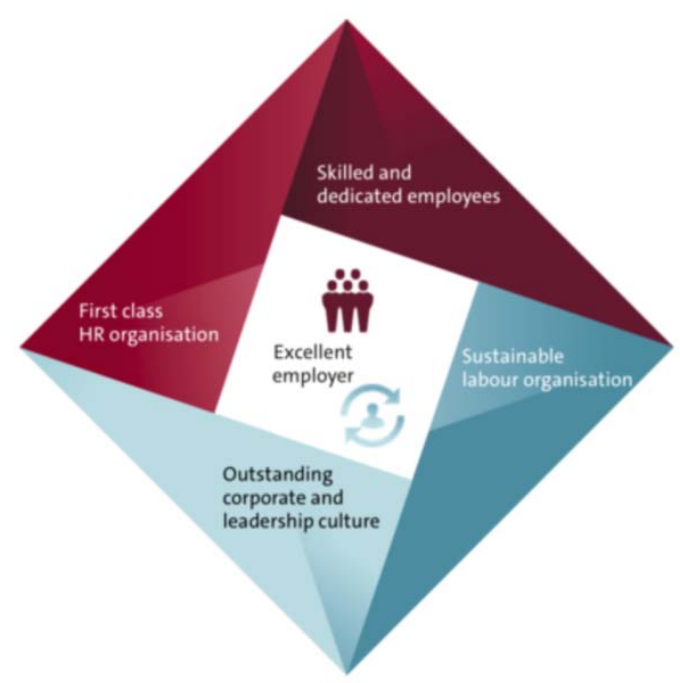

Figure 2. Strategic Objectives (Volkswagen Goals and Strategies, 2016)

The next strategic objective includes the corporate culture that was enhanced by Volkswagen to achieve an open and honest environment. The dimension also has various programs including equal opportunities for everyone and priority for women in order to remove the glass ceiling and allow women to grow and be able to combine work with family. The last but not the least is HR and the strategy "we empower to perform", and the vision of VW requires continuous improvement of human resources in order to motivate people to perform their best. Another guideline is HR being the foundation and support for change and transformation processes.

The first research objective has been raised to ascertain the link between current programs that Volkswagen offers and the retention rates. In the article "Increasing employee engagement: The role of interpersonal leadership" (2015) the author has emphasized that when satisfaction levels are high, employees feel the sense of belongingness that creates a bond with the organization and, therefore, increases organizational commitment. Volkswagen works for their employees and through that support provided for each individual within the organization, the company is able to create value and establish strong relationships.

\section{Retention Rates}

The VW scandal took place in 2015 and it would have been normal to see high turnover because people may not have wanted to be associated with the company that does harm to the environment. The retention rates are only one half of one percent, and figures can be found in Appendix 1. The total number of people employed in $\mathrm{VW}$ is more than 600 thousand (Appendix 2) which means that fewer than 3,000 employees leave the company on an annual basis.

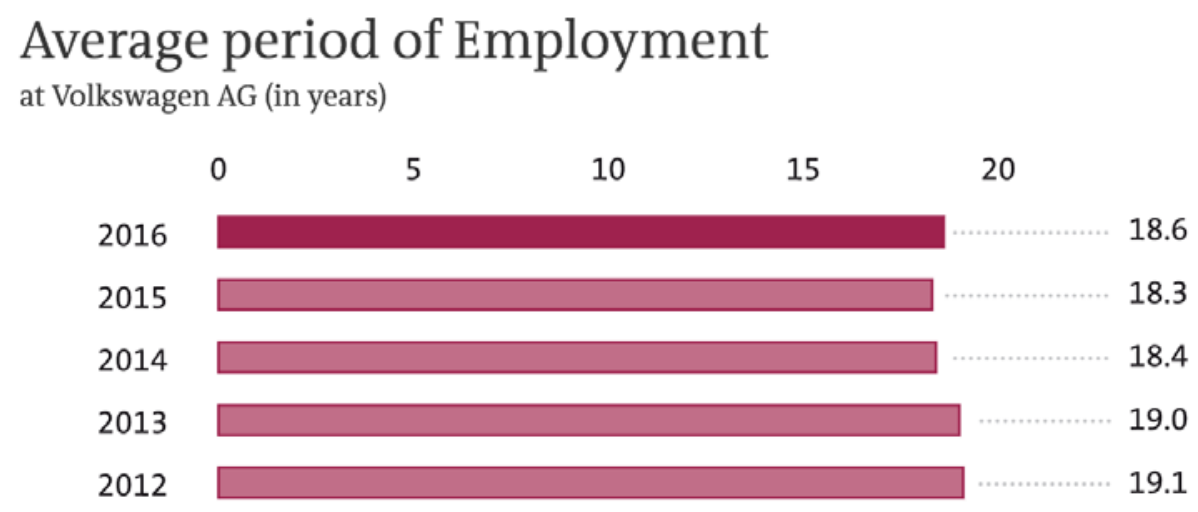

Figure 3. Average Period of Employment (Volkswagen Goals and Strategies, 2016)

The turnover costs can be high even for a well-established company and having a higher retention can save thousands in costs for replacement of just one employee. Laddha
(2012) has cited that in order to replace one employee on the entry-level position it will take 30-50 percent of annual salary whereas 150 percent for mid-level and 400 percent for 
specialized professionals. Most companies try to cut down on the turnover to at least 5-10 percent, and Volkswagen has succeeded in reaching $99.5 \%$ retention rate.

Volkswagen gives a lot of priorities to its employees, one of the many is the option to return to the company within 20 years of resignation and be reinstated at the same position. Moreover, the figure above shows the tenure of employees in the organization which is on average around 18 years. Therefore, all of the programs that VW offers have been successful in achieving high job satisfaction and organizational commitment that contributes to the employees wanting to stay with the company and being loyal throughout the ups and the downs of Volkswagen. In integrating employee engagement and empowerment, it is essential that further evidence be provided throughout the new strategy to perform empowerment and engagement programs. It is also important to motivate employees to participate and be part of the organization.

\section{CONCLUSION}

It is not enough to hire individuals to be successful and be able to compete in the modern world. The Human Resource function is indeed a critical dimension as it is given high importance by many existing companies, as well as various other programs to enhance the work environment. Among many is employee engagement and empowerment as a tool to decrease the organizational turnover. Although many might ignore retention, it is the aspect that can save a lot of money for the company and more importantly, allow keeping the best professionals within the organization. In 2017 in the study done by Prerana, the researcher was able to identify that there is a significant relationship between organizational commitment and employee engagement whereas Ukil (2016) has said that employee empowerment does not only contribute to the satisfaction of employee but also affects the quality of the service provided to the customers and their satisfaction with it.

Volkswagen is one of the examples of success in achieving high retention rates. However, in order to say that engagement and empowerment are the key success factors, the research needs a more extensive analysis. It is noted that those two factors have contributed more or less in decreasing turnover. The main purpose of engagement is to encourage the employee to participate. Many might say that they leave work because they could do much more than what they have been given, or be able to share their experiences and ideas (Prerana, 2017). And that is what Volkswagen does through many programs like Idea Management. Moreover, "We perform to empower" is a great strategy to remove high power distance and enable a much more open and faster decision-making process. Thus, employee engagement and empowerment can indirectly influence retention rates. Therefore, the importance of the two concepts cannot be ignored by any organizations.

\section{REFERENCES}

AG, V. (2016). Responsibility and Change Sustainability Report. Retrieved March 05, 2018, from http://sustainabilityreport2016.volkswagen ag.com/home.html

Al Rawi, S.M., Gernal, L.M, \& Sergio, R.P. (2011). Managing Talent for Competitive Advantage: Perspectives from Gulf Cooperation, International Journal of Multidisciplinary Research, 1 (1), pp. 116127.

Appelbaum, S. H., Karasek, R., Lapointe, F., \& Quelch, K. (2015). Employee empowerment: Factors affecting the consequent success or failure (part II). Industrial and Commercial Training, 4オ1), pp. 23-30.

Appelbaum, S., Karasek, R., Lapointe, F., \& Quelch, K. (2014). Employee empowerment: Factors affecting the consequent success or failure - part I. Industrial and Commercial Training, 467), pp. 379-386.

Crête, R. (2016). The Volkswagen scandal from the viewpoint of corporate governance. European Journal of Risk Regulation: EJRR, 71), pp. 25-31.

Frank, J. (2015). From engagement to empowerment - employee advocacy in the social economy. Strategic HR Review, 14(4), p. 144.

Gernal, L.M, Sergio, R.P., \& Shuali, M.A. (2013). Looking Ahead: Scanning Change Management and its Implications to Human Resource Management Practices, The International Journal of Business and Management, 7(1), pp. 1-17.

Ghosh, A. K. (2013). Employee empowerment: A 
strategic tool to obtain sustainable competitive advantage. International Journal of Management, 303), p. 95.

Guaspari, J. (2015). Why employee engagement isn't working. Strategic HR Review, 14(6), p. 10.

Haladay, D. J., Sergio, R. P., Makki, A. M., Zarim, Z. A., \& Ismail, M. N. (2017). Intercultural Competencies for Career Advancement: A Comparative Study of Managerial Competencies in United Arab Emirates and Malaysia. In Leadership, Innovation and Entrepreneurship as Driving Forces of the Global Economy. Springer, Cham. pp. 423430.

Haladay, D., Sergio, R., Opulencia, M. J., \& Antiado, D. (2016). Strategic Talent Management Practices in the United Arab Emirates, World Review of Business Research, 6(1), pp. 118 - 128.

Haladay, D. J. \& Sergio, R. P. (2016). The Impact of Demographic Variables on Managerial Competencies and Career Advancement. IAMURE International Journal of Business and Management, 13(1), p. 1.

Henderson, R., \& Reavis, C. (2009). What's Driving Porsche?.

Increasing employee engagement: The role of interpersonal leadership. (2015). Strategic Direction, 31(2), p. 34.

Laddha, A., Singh, R., Gabbad, H., \& Gidwani, G. D. (2012). Employee retention: An art to reduce turnover. International Journal of Management Research and Reviews, 2(3), p. 453.

Paillé, P. (2013). Organizational citizenship behaviour and employee retention: How important are turnover cognitions? The International Journal of Human Resource Management, 24(4), pp. 768-790.

Prerana. (2017). Effect of employee engagement on organisational commitment. Indian Journal of Commerce and Management Studies, $8(2), 101$.

Saks, A. M., \& Gruman, J. A. (2014). What do we really know about employee engagement? Human Resource Development Quarterly, 25(2), pp. 155-182.

Sandhya, K., \& Kumar, D. P. (2014). Employee retention - A strategic tool for organizational growth and sustaining competitiveness. Journal of Strategic Human
Resource Management, 3(3)

Sergio, R.P., Dungca, A.P., Ormita, L.A., Gonzales, J.O. (2015). Emotional Intelligence, WorkFamily Conflict, and Work Values among Customer Service Representatives: Basis for Organizational Support, Journal of Eastern European and Central Asian Research, 2(1), pp. 218-224.

Sergio, R. P., Moyalan, L. J., Al-Ali, H. R., \& Al Bannai, M. M. (2017). Human Resource Management Practices: A Case of Telecommunication Company in the United Arab Emirates. In Leadership, Innovation and Entrepreneurship as Driving Forces of the Global Economy (pp. 437-444). Springer, Cham.

Sergio, R.P., Ormita, L.A., \& Dungca, A.P. (2015). The Demographic Variables and Emotional Intelligence as Correlates of Work Attitudes towards Organizational Development, Journal of Economics and Business Management, 6(2), pp. 45-64.

Ukil, M. I. (2016). The impact of employee empowerment on employee satisfaction and service quality: Empirical evidence from financial enterprizes in Bangladesh. Verslas: Teorija Ir Praktika, 17(2), 178-189.

Volkswagen Goals and Strategies. (2016). Retrieved March 05, 2018, from http://annualreport2016.volkswagenag.com /group-management-report/goals-andstrategies.html

Zarim, Z. A., Mohamad, O., Rahman, M. S., Zaki, H. O., Sergio, R. P., \& Haladay, D. J. (2017). The Role of Organisational Commitment, Leadership Style, Strategic Human Resources Practices and Job Satisfaction Towards Sustainable Tourism Industry: Comparative Study in the UAE and Malaysia. In Leadership, Innovation and Entrepreneurship as Driving Forces of the Global Economy. Springer, Cham. pp. 255268. 


\section{ABOUT THE AUTHOR}

Rommel Sergio: email@rommelsergio.com

Dr. Rommel Sergio holds a PhD in Management (with high distinction) at the University of Liverpool, UK in 2015 and has earned his PhD in Psychology (summa cum laude) at De La Salle University-Dasmarinas, Philippines in 2008. He also acquired his Post-Doctoral Bridge to Business in Management certificate at Tulane University, New Orleans, Louisiana, USA in 2011. He is currently the Human Resource Management Program Chair and Associate Professor at the Canadian University of Dubai, United Arab Emirates. Dr. Sergio was awarded certified by the AACSB (The Association to Advance Collegiate Schools of Business) in Florida, USA as AQ (Academically Qualified) to teach in Management. He has also published and coauthored several academic research papers that were presented in a number of international academic conferences, including Harvard University.

Ms. Maria Rylova obtained her Bachelor of Business Administration degree in Finance and Accounting in 2016 at Canadian University of Dubai (magna cum laude) and currently completing Master degree in General Management and Finance at CUD. Rylova has participated in the 3rd annual student competition conducted by Society for Human Resource Management in the Middle East and North Africa region, and has been chosen as one of the finalists with her team. 


\section{APPENDICES}

\section{Appendix 1 - Employee Turnover}

Ideas Management in the Volkswagen Group*

\begin{tabular}{lrr}
\hline Ideas suggested & 2016 & 2015 \\
\hline Suggestions implemented & 583,017 & 536,081 \\
\hline Savings (Emillion) & 482,453 & 360,454 \\
\hline Bonuses (Emillion) & 435.6 & 374.9 \\
\hline & & 40.0 \\
\hline
\end{tabular}

\section{Appendix 2 - Number of Employees and Proportion of Women}

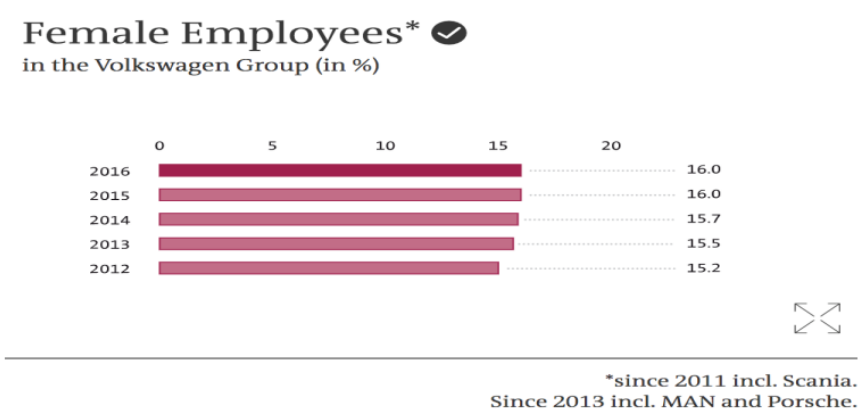

\section{Number of Employees}

in the Volkswagen Group by Type of Work

\begin{tabular}{|c|c|c|c|c|c|}
\hline & 2016 & 2015 & 2014 & 2013 & 2012 \\
\hline Production workers & 289,438 & 279,771 & 273,418 & 265,474 & 258,685 \\
\hline Non-production workers & 317,787 & 311,654 & 300,709 & 289,623 & 274,364 \\
\hline Apprentices & 19,490 & 18,651 & 18,459 & 17,703 & 16,714 \\
\hline Total workforce & 626,715 & 610,076 & 592,586 & 572,800 & 549,763 \\
\hline of whom: active employees ${ }^{*}$ & 601,443 & 585,242 & 566,998 & 545,596 & 525,245 \\
\hline in passive phased retirement & 5,782 & 6,183 & 7,129 & 9,501 & 7,804 \\
\hline
\end{tabular}

-All employees with a current contract of employment in a Group company who are involved in the value creation process. 


\section{Appendix 3 - Ideas Management}

\section{Employee Turnover* $\bullet$}

at Volkswagen AG (in \%)

\begin{tabular}{|c|c|c|c|c|c|}
\hline & 2016 & 2015 & 2014 & 2013 & 2012 \\
\hline Women & 0.3 & 0.4 & 0.3 & 0.3 & 0.2 \\
\hline Men & 0.5 & 0.4 & 0.4 & 0.4 & 0.4 \\
\hline Total & 0.5 & 0.4 & 0.4 & 0.4 & 0.4 \\
\hline
\end{tabular}

${ }^{*}$ Not incl. age-related turnover. 